\title{
Appendiceal Carcinoma pT4 TNM Finding v8
}

National Cancer Institute

\section{Source}

National Cancer Institute. Appendiceal Carcinoma pT4 TNM Finding v8. NCI Thesaurus.

Code $C 134100$

Appendiceal carcinoma with tumor invading the visceral peritoneum, including the acellular mucin or mucinous epithelium involving the serosa of the appendix or mesoappendix, and/or directly invading adjacent organs or structures. (from AJCC 8th Ed.) 